\title{
Parents' Usage of a Kindergarten Smart Campus System: An Exploration of the Continuance Intention Factors
}

\author{
Mingming Shao, Jinyan Yu* \\ School of Education Science, Nanjing Normal University, Nanjing, China \\ Email: ^1327890863@qq.com
}

How to cite this paper: Shao, M. M., \& Yu, J. Y. (2021). Parents' Usage of a Kindergarten Smart Campus System: An Exploration of the Continuance Intention Factors. Chinese Studies, 10, 156-174.

https://doi.org/10.4236/chnstd.2021.103010

Received: July 18, 2021

Accepted: August 13, 2021

Published: August 16, 2021

Copyright ( 2021 by author(s) and Scientific Research Publishing Inc. This work is licensed under the Creative Commons Attribution International License (CC BY 4.0).

http://creativecommons.org/licenses/by/4.0/

\section{(c) (i) Open Access}

\begin{abstract}
In today's digital age, the innovation of smart campuses can bring convenience to the instruction and management of schools. However, parents' support with continued usage determines the application and implementation of smart campus system (SCS). Thus, it is necessary to explore the parents' continuance intention factors of usage of SCS. Based on the existing studies and theories on continuance intention to use (CIU), a research model composed of ten hypotheses was designed to test what factors could predict the kindergarten parents' $\mathrm{CIU}$ and the expectancy-confirmation factors. From the data analysis, we could conclude that satisfaction, perceived usefulness, expectation confirmation, subjective norms, and perceived ease of use were positively correlated. It is hoped that the results can be a reference for SCS system designers and managers to improve the SCS implementation in order to facilitate kindergarten children's learning.
\end{abstract}

\section{Keywords}

Smart Campus System, Innovation, Kindergarten Parents, Continuance Intention to Use

\section{Introduction}

Under the smart learning environment created by the Internet of Things (IOT), all campus activities are expected to be effective and efficient (Sari et al., 2017). Given the need to actively address the usage of technology, educational leaders have a growing interest in constructing smart campuses which is a school where technology devices and apps create new experiences or services and improve operational efficiency (Zaballos et al., 2020). That is, smart campuses promote a 
convenient campus network, innovative scientific research, and efficient administrative management (Coccoli et al., 2014). Currently, many smart technologies have been put into smart campuses to monitor and analyze teaching activities (Zhao et al., 2021a, 2021b). Such systems have significantly improved the efficiency and quality of student learning engagement (Raes et al., 2020), and have provided students with reliable conveniences in their academic and social life (Abdrabbah et al., 2018). Nowadays, some discussions have been focused on the understanding of the technology application of smart kindergarten management (He et al., 2014; Pagliaro et al., 2016), the learning effects and children's behavior information with sensor connections and the Global Positioning System (GPS) (Singh et al., 2019). In line with the design of GPS, smart campus system (SCS) has been implemented in some kindergartens. SCS is also important for enhancing home-school partnerships in kindergartens (Lau \& Ng, 2019). Permission and support should be gained from kindergarten parents. Thus, the present study focused on kindergarten parents' acceptance and attitudes toward engaging with SCS.

To raise the standard of education, SCS has been successfully incorporated into the education system (Bi et al., 2017). However, parents' support of the use of SCS in instruction and management is still not clear (Gao et al., 2017). The information literacy of parents is not high, and the acceptance of information technology is lack of initiative, resulting that the use of information technology is difficult (Liu \& Liu, 2020). To discuss this issue, this study adopted the expectation-confirmation theory (ECT) (Oliver, 1980) to explore the understanding of information system usage. ECT delineates a process model in which an individual compares their pre-usage expectations about a product or service to their post-usage perceptions of the product or service to determine the extent to which their expectations are confirmed, which is then utilized to determine their level of satisfaction/dissatisfaction. In this process, an individual assesses their post-usage belief about the performance of a product (or service) against their pre-usage expectations of how the product (or service) should perform (Cadotte et al., 1987). The performance can be better, the same as, or worse than expected. If the performance is the same as was expected, the outcome is termed as "confirmation". However, if the performance is better or worse than expected, then "disconfirmation" occurs (Oliver, 1980). ECT is increasingly being used in the field of information systems to predict and interpret intentions for continuance intention to use (CIU) (Bhattacherjee, 2001). For example, Chou et al. (2012) argued that the ultimate success of a technology depends more on the users' continued use of the system than on their initial adoption. Additionally, Bhattacherjee (2001) argued that perceived usefulness and perceived ease of use may influence subsequent continuance decisions regarding information system (IS) usage. Extended from the ECT framework, the present study used the constructs, satisfaction, expectation confirmation, and perceived usefulness and ease of use from the modified ECT to understand Chinese parents' CIU related to a 
SCS. It is hoped that the findings of this study could provide valuable information for kindergarten designers and managers to better implement smart campuses.

\section{Literature Review}

\subsection{Smart Kindergarten Campuses}

The smart kindergarten in this study, also called a smart kindergarten campus, is a common concept similar to a smart campus. The term "smart campus" is different from the traditional campus; in this concept, cloud computing, IOT and other internet technologies are connected with the campus teaching, research, management and campus resources, and integrate different information system platforms to form a unified information management platform (Chao, 2017; Kwok, 2015). Comparing the input and output of smart campus construction, many studies based on smart campuses have been conducted with a focus on the technology (Torres-Sospedra et al., 2015; Van Merode et al., 2016; Luo, 2018), application, and learning outcomes evaluation (Xu et al., 2018). Catering to the needs of teachers and students has popularized the use of intelligence, with an increasing number of scholars having explored smart college campus systems. For example, Wang and Yan (2018) designed a mobile smart campus system and found that it provides the college with a ubiquitous learning space that combines innovative network research, transparent and efficient school management, colorful campus culture, and convenient and thoughtful campus life. Yang et al. (2018) developed a situational awareness smart campus system and found that it was convenient for decision makers to make corresponding decisions, and the campus application was better able to serve teachers and students.

Nowadays, the construction of SCS in Chinese kindergartens is still in its infancy. Only a few kindergartens have applied a SCS to facilitate teaching and school management. The main reason for this slow adoption is the attitudes of the parents. For example, one study indicated that most parents asserted that students should not be allowed to use mobile phones during classes and examinations (Gao et al., 2017). Nevertheless, due to their perceived ease of use, perceived usefulness, and connectedness to multiple sources of technology, Lee et al. (2014) expected that in the future, smart systems for early childhood education would be increasingly common. Therefore, this study focuses on parents' CIU on SCS in kindergartens.

\subsection{Continued Intention to Use}

Apart from ECT, there are two other theoretical models, Technology Acceptance Model (TAM) and Information Systems Acceptance Model (ISAM), widely used in the field of Management Information Systems to explore the adoption and success of information systems (Chou et al., 2012). TAM derived from Davis (1989), has become a powerful model for predicting usage intentions and acceptance of new information technologies. The other theory proposed by Davis, 
ISAM, based on TAM which is derived from the social psychology literature has also been developed to systematically assess and interpret users' usage intentions and satisfaction. Perceived usefulness means "the degree to which a person believes that using a particular system can improve his or her job performance." Perceived ease of use is "the degree to which one believes that using a particular system is effortless" (Davis, 1989: p. 320). The two variables predict users' attitude towards using the product.

Bhattacherjee (2001) proposed the Post-Acceptance Model (PAM) of IS continuance to extend Oliver's ECT theory. In his model, four variables, perceived usefulness, confirmation, satisfaction and IS continuance intention, were proposed. He stated that perceived usefulness predicts satisfaction and IS continuance intention. The satisfaction variable is predicted by perceived ease of use and usefulness and confirmation (Gan \& Balakrishnan, 2018). Aimed at a particular product or IS, and integrating different theories, the CIU model was developed to explain those factors which play a prediction role (Rahman et al., 2017). Moreover, Mouakket (2015) proposed the expectation-confirmation model by exploring the subjective norms as key factors, and found that they could directly predict continuance usage intention. Taken together, the present study proposed the SCS success model to analyze six factors of ECT.

\section{Method}

\subsection{Research Model and Hypotheses}

Due to the convenience of smart technology, many parents support its use and feel that it should be adopted in preschool education as an opportunity to prepare their children for the future (Erdogan et al., 2019). Conversely, due to parents being new to technology change, their attitudes towards adopting smart technologies play a major role in understanding the educational value of the usage of smart technologies, particularly in kindergartens (Papadakis et al., 2019).

Confirmation of previous factors such as subjective norms will predict user satisfaction and perceived usefulness, and predict CIS of IS (Cheng \& Yuen, 2018; Joo et al., 2018). Extending from expectation-confirmation theory (ECT), the present study explored a model with the variables which are assumed to directly or indirectly predict the parents' CIU of a smart campus in a kindergarten (see Figure 1).

To understand this controversy with the research model, the present study proposed the following hypotheses:

H1: Parents' US is positively related to their CIU.

$\mathrm{H} 2$ : Parents' EC is positively related to their US.

H3: Parents' PEU is positively related to their PU.

H4: Parents' PU is positively related to their US.

H5: Parents' PEU is positively related to their US.

H6: Parents' PU is positively related to their EC. 


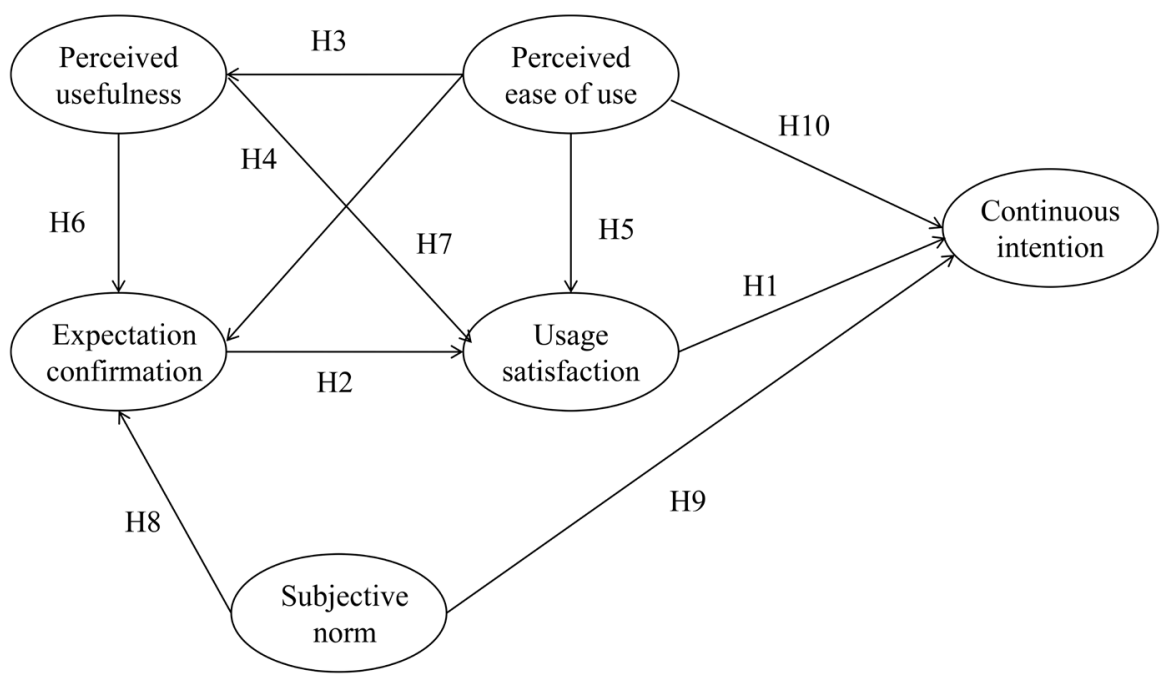

Figure 1. Research model.

H7: Parents' PEU is positively related to their EC.

H8: Parents' SN is positively related to their EC.

H9: Parents' SN is positively related to their CIU.

H10: Parents' PEU is positively related to their CIU.

\subsection{Research Setting}

It has been more than two years since the experimental kindergartens applied SCS in their campuses. Not all the classes implemented the SCS. Only a few classes adopt the system. Therefore, it is still the beginning stage of the application of the smart campus construction for these kindergartens.

The current functions of the SCS in the kindergartens include collecting check-in and check-out time, deep sleeping duration, and the duration of one particular learning activity through a wristband with one sensor for each child. The check-in and check-out system relies on the wristband touching a sensor node which is designed to look like a robot standing at the school entrance. When the child uses his/her wristband to touch the robot, it says hello. Parents and teachers can get the exact check-in and check-out time. It is easy to calculate the deep sleeping duration by checking children's heart rate with the wristband. Learning activities in the kindergartens could be divided into indoor and outdoor activities. Indoor activities mainly include learning activities occurring in different learning areas similar to the curricular areas of Practical life, Sensorial, Language, Mathematics and Geometry, Geography, Music, Art, and Culture in Montessori education (Montessori, 1967, 1989a, 1989b). Outdoor activities are the activities of physical education and other games. With the wristband, children's positions could be detected with the help of the Internet, and the duration of one particular learning activity is easily calculated so as to check children's learning interest and engagement in that learning activity.

Using a data cloud, the data from each child's wristband are stored and computed to be analyzed by experts and teachers to form knowledge and wisdom for 
teachers and parents. The experts are proficient in computers and big data, and the teachers have rich teaching experience. Based on their knowledge and wisdom, teachers could redesign or reorganize their learning activities, and parents could conduct their family education to cooperate well with the school education (see Figure 2).

Most of the parents might not understand the detailed construction of the kindergarten SCS, and how the SCS works or its benefits, especially the technology applied. However, they learned about all of the functions and applications of the entire SCS through face-to-face training conducted by the kindergarten for about one hour. The SCS tutorial made in Microsoft PowerPoint, including the functions and usage instruction of the SCS, was sent to the parents as well. The parents could install the SCS application (APP) on their own mobile devices, enabling them to check the record of their children's activities. Figure 3 shows the screenshot of the interface of the SCS APP. There are five buttons at the bottom of the interface: kindergarten, dynamic, health, parenting and me. The current interface shows the health record of the child's one-whole-day morning examination, check-in time, morning exercise performance, description of deep sleeping and activity performance. The kindergarten interface will show any notices from the kindergarten. Parents can check their child's learning activities in the dynamic interface. The parenting interface is to show information for family education. The interface of "me" is the child's personal information. The tutorial also declared that the data from the SCS was safe and would be used for promoting kindergarten teaching and management, rather than for commercial use or any other purposes.

The wristband is the only way to collect the information of the children's in-campus behaviors and learning activities. The children are required to wear their wristbands from the beginning to the end of the school day. Therefore, the parents have to remind their children to wear the wristband every day when they

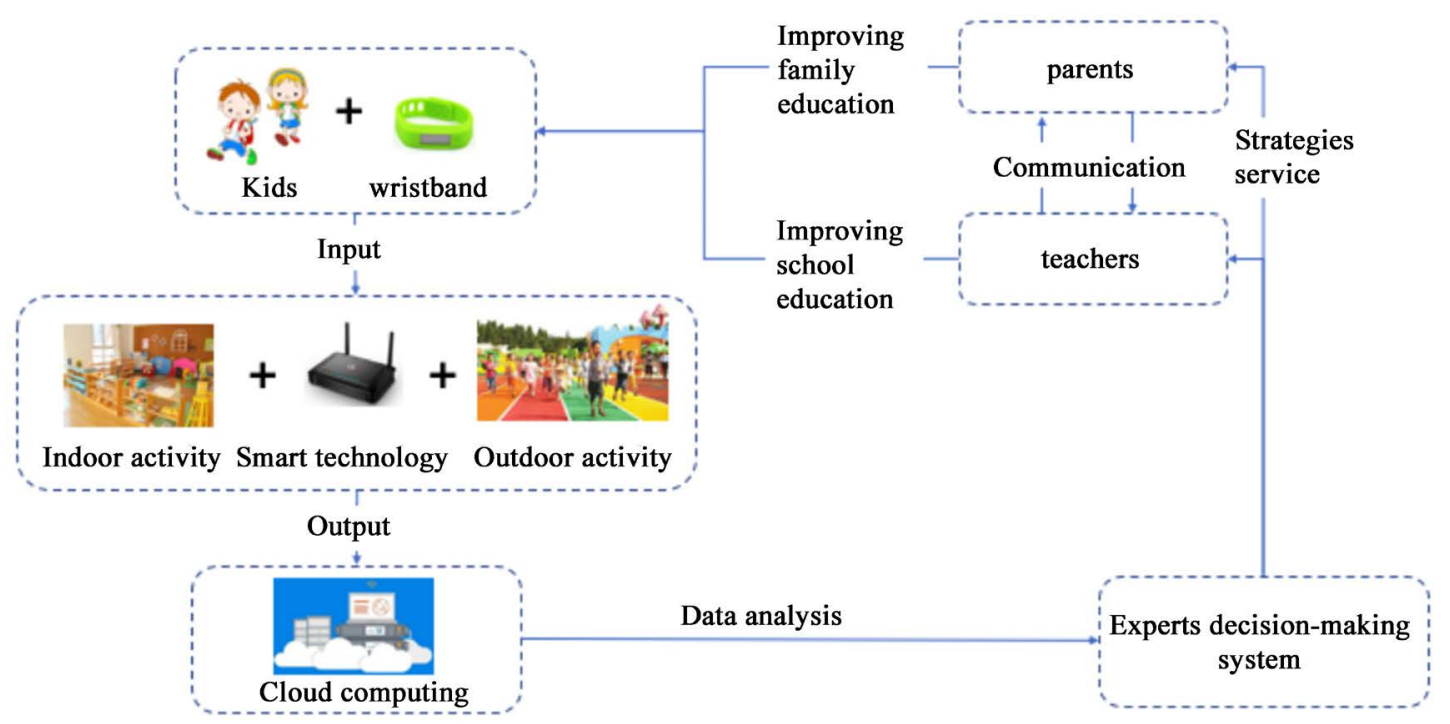

Figure 2. Kindergarten smart campus system (SCS). 


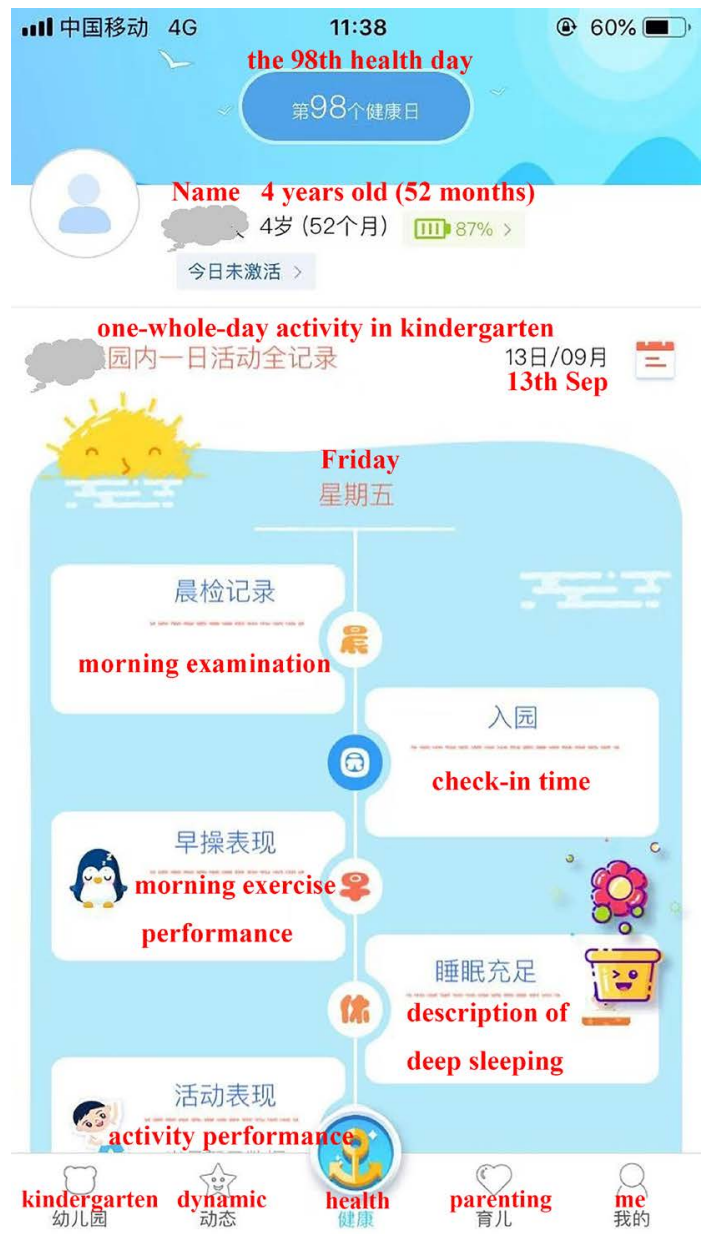

Figure 3. Interface of the SCS APP.

go to school. From the beginning of the implementation of the SCS more than 2 years ago to now, all the parents permitted their children to wear the wristband to the kindergarten every day.

The participating parents of the children accepted and experienced the SCS for at least two semesters. They had become familiar with the SCS and supported the behavior of wearing a wristband from the beginning of its application. However, with the application of the SCS for all classes and its expanding functions, in contrast to accepting the SCS, the study on the parents' CIU is meaningful for the further development and implementation of the SCS.

\subsection{Instrument}

Adapted from previous theories or studies (Bhattacherjee, 2001; Hsiao et al., 2016; Venkatesh et al., 2003), the questionnaire items were professionally translated into Chinese and subjected to accuracy checking by experts to ensure their face validity. There were two parts to the questionnaire. The first was demographic information, including three questions (see Table 1). The second part was designed to measure the factors. They were measured using 5-point Likert scales $(1=$ strongly disagree, $2=$ disagree, $3=$ neutral, $4=$ agree, $5=$ strongly 
agree), consisting of perceived usefulness (eight items), perceived ease of use (five items), expectation confirmation (three items), subjective norms (three items), usage satisfaction (four items), and CIU (four items). The questionnaire items which remained after the internal and external validity analyses were further subjected to reliability and validity tests. Moreover, the reliability and validity of the questionnaire were tested after the data were collected.

Perceived usefulness measuring: $\mathrm{PU}$ in the model means the degree to which the parents believed that utilizing the SCS would enhance their family education and cooperation with school education for their children. Questions were designed based on the studies of Venkatesh et al. (2003); exemplary items are "The check-in and check-out robot is convenient and friendly" and "I am so relieved that I can watch my child's check-in and check-out video."

Perceived ease of use measuring: PEU means the degree to which the parents believe that using the SCS would be free of effort. Questions were designed according to the studies of Venkatesh et al. (2003); exemplary items are "I always forget to remind my child to wear the wristband to school" and "I think the user interface of the SCS application on my mobile device is friendly and easy to use."

Expectation confirmation measuring: EC was the degree of the gap of parents' pre-use and use expectation of the SCS, which is based on the study of Bhattacherjee (2001); exemplary items are "The functions of the wristband are more than I imagined before" and "It has become a part of my life to check the application."

Subjective norm measuring: SN referred to the prediction of other people's decisions on the parents' use of the SCS. Three questions were based on the studies of Venkatesh et al. (2003); exemplary questions were "Teachers in the kindergarten suggest that I use the wristband and the SCS application" and "My child's classmate is wearing the wristband and I think my child will do so too."

Usage satisfaction measuring: US referred to the experience of the whole usage of the SCS by the parents. Its measurable questions were based on the studies of Bhattacherjee (2001); exemplary items are "I am satisfied with using the SCS application" and "It is a wise choice to use the SCS application for me."

Continuous intention to use measuring: CIU was the intention of parents' continuing usage of the SCS, including their agreement with and support of their children's wristband wearing, the use of the SCS app, etc. CIU was measured by four questions based on the studies of Hsiao et al. (2016); exemplary questions are "It is a habit for me to check the information in the application to know my child's in-school performance and activities" and "It is a natural behavior for me to use the SCS application and insist on asking my child to wear the wristband."

\subsection{Participants and Procedure}

The participants of the study were from three kindergartens. The survey was conducted at the end of the 2019-2020 school year. There were 522 parents from 18 classes who participated in the survey (each class has about 29 children, with 
one parent per child participating). The questionnaire was sent to an online survey tool named Questionnaire Star, then a cover letter was sent to participants' emails to ask them to link to the questionnaire website and reply to those questionnaire items. In the preface of the questionnaire, participants were told that they were participating in a study that the data they provided was anonymous, and the study data might be published.

However, after removing incomplete returns, and after the useful data were subjected to first-order confirmatory factor analysis, a total of 6 samples were deleted. Table 1 shows the number and percentage of the profile of the remaining 516 samples. The frequency of checking the app on their mobile devices was also mentioned in the survey (see Table 1).

\section{Results}

Structural equation modeling (SEM) could be used to confirm direct, indirect, and mediating relationships (Sin \& Kim, 2013), and could test the research model. According to Kline's (2005) recommendation, the sample size $(\mathrm{n}=516)$ was considered sufficient for AMOS to obtain reliable results in structural equation modeling. Therefore, the present study tested Confirmatory Factor Analysis (CFA) and path analysis with SEM using AMOS 24.0.

\subsection{Mean and Standard Deviation}

Using SPSS, the mean and standard deviation of the questionnaire were calculated as Table 2. The mean value of each item of the questionnaire was more than 3.5. The value of the standard deviation was less than 1.4.

\subsection{Reliability and Validity Analysis}

A survey was conducted with a small sample before the formal survey. Some questions were deleted or revised according to the study context. The software of SPSS 24.0 was used to test the validity and reliability of the questionnaire. The

Table 1. Profile of participants by parents.

\begin{tabular}{cccc}
\hline \multicolumn{1}{c}{ Variable } & Classification & Count & Percentage \\
\hline \multirow{2}{*}{ Gender } & Male & 213 & $41.3 \%$ \\
& Female & 303 & $58.7 \%$ \\
\hline Child's Grade & Nursery grade & 308 & $59.7 \%$ \\
& Lower-kindergarten & 96 & $18.6 \%$ \\
& Upper-kindergarten & 112 & $21.7 \%$ \\
\hline $\begin{array}{c}\text { Frequency of checking the app } \\
\text { on their mobile devices }\end{array}$ & Once every few days & 62 & $12.0 \%$ \\
& Once a day & 159 & $30.8 \%$ \\
& More than once a day & 48 & $47.9 \%$ \\
\hline
\end{tabular}


Table 2. Mean and standard deviation $(n=516)$.

\begin{tabular}{|c|c|c|c|}
\hline & Item & Mean & Standard deviation \\
\hline \multirow{8}{*}{ PU } & PU1 & 3.85 & 1.276 \\
\hline & PU2 & 3.74 & 1.245 \\
\hline & PU3 & 3.82 & 1.212 \\
\hline & PU4 & 3.75 & 1.211 \\
\hline & PU5 & 3.77 & 1.204 \\
\hline & PU6 & 3.77 & 1.193 \\
\hline & PU7 & 3.78 & 1.130 \\
\hline & PU8 & 3.77 & 1.193 \\
\hline \multirow{5}{*}{ PEU } & PEU1 & 3.57 & 1.247 \\
\hline & PEU2 & 3.75 & 1.300 \\
\hline & PEU3 & 3.78 & 1.307 \\
\hline & PEU4 & 3.78 & 1.252 \\
\hline & PEU5 & 3.73 & 1.302 \\
\hline \multirow{3}{*}{$\mathrm{EC}$} & $\mathrm{EC} 1$ & 3.76 & 1.134 \\
\hline & EC2 & 3.77 & 1.178 \\
\hline & EC3 & 3.77 & 1.171 \\
\hline \multirow{3}{*}{$\mathrm{SN}$} & SN1 & 3.98 & 1.067 \\
\hline & SN2 & 3.98 & 1.059 \\
\hline & SN3 & 3.99 & 1.095 \\
\hline \multirow{4}{*}{ US } & US1 & 4.01 & 1.095 \\
\hline & US2 & 4.01 & 1.111 \\
\hline & US3 & 4.02 & 1.086 \\
\hline & US4 & 3.93 & 1.118 \\
\hline \multirow{4}{*}{$\mathrm{CIU}$} & CIU1 & 3.92 & 1.109 \\
\hline & CIU2 & 3.90 & 1.129 \\
\hline & CIU3 & 3.92 & 1.094 \\
\hline & CIU4 & 3.84 & 1.136 \\
\hline
\end{tabular}

study applied Cronbach's alpha, average variance extracted (AVE), and composite reliability (CR) to assess the model data reliability and validity (see Table 3 ). Cronbach's alpha is used to measure the internal consistency of data. Reliability is the degree to which a measure is free from error and yields consistent results (Hair et al., 2010). The Cronbach's alpha of each item in the questionnaire is above .7 (Nunnally \& Bernstein, 1994) (see Table 2) thus showing that the data reliability of the study is acceptable. The study used confirmatory factor analysis to measure the discriminant validity and convergent validity. Based on the finding of Fornell and Larcker (1981), the convergent validity can be measured by 
CR, AVE, and indicator factor loading. An acceptable value of the indicator factor loading is 0.5 or above (Hair et al., 2010). The value of CR and AVE should be 0.7 and 0.5 or above (Fornell \& Larcker, 1981). The results of the value CR and AVE in the study all showed acceptable values, which indicated the validity of the measures (see Table 3).

As suggested by Fornell and Larcker (1981), discriminant validity is determined when the square root of the AVEs is greater than the inter-construct correlations. Table 4 showed that the square root of the AVEs of the study was greater, which indicated acceptable discriminant validity.

\subsection{Model Fit Assessment}

In the study, Confirmatory Factor Analysis (CFA) (Anderson \& Gerbing, 1988) was applied to conduct model fit assessment. The following fit indices, chi-square normalized by degree of freedom (Chi-square/df), the goodness-of-fit statistic (GFI) (Tabachnick \& Fidell, 2007), the adjusted goodness-of-fit statistic (AGFI) (Tabachnick \& Fidell, 2007), normed-fit index (NFI) (Bentler \& Bonnet, 1980), comparative fit index (CFI) (Bentler, 1990), and root mean square error of approximation (RMSEA) (Steiger, 1990) were calculated to assess the measurement model.

We conducted the SEM analysis on the structural model and found that the Chi-square/df was 2.447, which was under the acceptable threshold level of 5.0

Table 3. Reliability and validity analysis.

\begin{tabular}{ccccc}
\hline & $\begin{array}{c}\text { Construct Factor } \\
\text { loading }\end{array}$ & Cronbach's alpha & $\begin{array}{c}\text { Composite } \\
\text { reliability (CR) }\end{array}$ & $\begin{array}{c}\text { Average variance } \\
\text { extracted (AVE) }\end{array}$ \\
\hline PU & 0.910 & 0.974 & 0.9746 & 0.8275 \\
PEU & 0.921 & 0.966 & 0.9655 & 0.8485 \\
EC & 0.914 & 0.950 & 0.9382 & 0.8351 \\
SN & 0.906 & 0.932 & 0.9322 & 0.821 \\
US & 0.911 & 0.954 & 0.951 & 0.8291 \\
CIU & 0.904 & 0.954 & 0.9469 & 0.8168 \\
\hline
\end{tabular}

Table 4. Reliability and validity analysis Construct discriminant validity analysis.

\begin{tabular}{ccccccc}
\hline & PU & PEU & EC & SN & US & CIU \\
\hline PU & 0.910 & & & & & \\
PEU & $0.823^{* *}$ & 0.921 & & & & \\
EC & $0.781^{* *}$ & $0.794^{* *}$ & 0.914 & & & \\
SN & $0.475^{* *}$ & $0.407^{* *}$ & $0.586^{* *}$ & 0.906 & & \\
US & $0.773^{* *}$ & $0.803^{* *}$ & $0.740^{* *}$ & $0.591^{* *}$ & 0.911 & \\
CIU & $0.827^{* *}$ & $0.820^{* *}$ & $0.815^{* *}$ & $0.562^{* *}$ & $0.823^{* *}$ & 0.904 \\
\hline
\end{tabular}

Note: ${ }^{* *} p<0.01,{ }^{* * *} p<0.001$. 
(Bentler \& Bonett, 1980). The value of RMSEA was 0.053, which is less than the value of 0.08 (Anderson \& Gerbing, 1988). The values of NFI and CFI were 0.960 and 0.976 , which are both above the acceptable value of 0.90 (Hair et al., 2010). The values of GFI and AGFI were 0.907 and 0.888 , which are more than the suggested value of 0.80 and less than 1.0 (Foster et al., 2006). Thus, the results showed a good model fit.

\subsection{Hypotheses Testing}

In the path model a standardized path coefficient (beta, $\beta$ ) shows the direct effect of an independent variable on a dependent variable. The value of $\beta$ is between -1 and 1 . If the value is less than 0 , the effect of an independent variable on a dependent variable is negative. The larger the absolute value of $\beta$ is, the greater the effect of an independent variable on a dependent variable is. The value of $p$ indicates the degree of significance of prediction. The acceptable value of $\mathrm{p}$ is less than 0.05 . US was positively related to CIU (H1: $\beta=0.362, p<0.001)$. EC was positively related to US $(\mathrm{H} 2: \beta=0.224, p<0.001)$. PEU was positively related to PU (H3: $\beta=0.835, p<0.001$ ). PU was positively related to US (H4: $\beta=0.233, p$ $=0.003)$. PEU was positively related to US (H5: $\beta=0.363, p=0.006)$. PU was positively related to EC (H6: $\beta=0.243, p<0.001)$. PEU was positively related to EC (H7: $\beta=0.510, p<0.001)$. Parents' SN was positively related to their EC (H8: $\beta=0.338, p<0.001$ ). Parents' SN was positively related to their CIU (H9: $\beta=$ $0.179, p<0.001$ ). Parents' PEU was positively related to their CIU (H10: $\beta=$ $0.458, p<0.001$ ). Table 5 showed the standardized path coefficient for hypothesis testing. The 10 hypotheses were all positively supported.

The determination coefficient $r^{2}$ quantifies the variance ratio interpreted by the statistical model. We consider that $0.3-0.6$ of $r^{2}$ is medium, and less than 0.3 is low (Sanchez \& Golding, 2013). In addition, the model effect size $\left(f^{\not}\right)$ allows researchers to move from a simple recognition of statistical significance to a more general quantifiable description of the size of the effect (Fritz et al., 2012). $f$ values

Table 5. Standardized path coefficient for hypothesis testing.

\begin{tabular}{ccccc}
\hline Hypothesis & $\beta$ & S.E. & C.R. & $p$ \\
\hline H1 & 0.362 & 0.052 & 6.985 & $* * *$ \\
H2 & 0.224 & 0.048 & 4.678 & $* * *$ \\
H3 & 0.835 & 0.034 & 24.220 & $* * *$ \\
H4 & 0.233 & 0.051 & 4.569 & $* * *$ \\
H5 & 0.363 & 0.055 & 6.637 & $* *$ \\
H6 & 0.243 & 0.051 & 4.765 & $* * *$ \\
H7 & 0.510 & 0.050 & 10.243 & $* * *$ \\
H8 & 0.338 & 0.032 & 10.495 & $* * *$ \\
H9 & 0.179 & 0.030 & 6.045 & $* * *$ \\
H10 & 0.458 & 0.042 & 10.889 & $* * *$ \\
\hline
\end{tabular}


greater than 0.8 can be considered large. When it is between 0.2 and 0.8 , it can be considered medium, and when it is less than 0.2 , it can be considered small. In this study, the explanatory power of PEU on PU is $73 \%\left(r^{2}=0.73, f=2.70\right)$, and the explanatory power of PU, PEU and EC on US is $73 \%\left(r^{2}=0.73, f^{2}=\right.$ 2.70). The explanatory power of PU, PEU and SN on EC is $75 \%\left(r^{2}=0.75, f=\right.$ $3)$, and the explanatory variance of PEU, US and SN on CIU is $80 \%\left(r^{2}=0.80, f\right.$ $=0.4$ ). Hence, the six variables in this study have good predictive power (Hair et al., 2014) as shown in Figure 4.

\section{Discussion}

Meyer et al. (2019) propose that if parents do not view smart technology as an efficient method to promote their children's learning, they may not support the implementation of smart technology in schools. Many parents support smart technology and feel that it should be involved in the curricula of preschool education (Erdogan et al., 2019). On the other hand, some parents have negative attitudes towards the use of smart technology in schools (Ebbeck et al., 2016). To understand this issue, this study adopted the related theories to explore the correlates between variables of PU, PEU, EC, SN, and US that are assumed to predict the parents' CIU. Briefly, according to the results, PEU, SN, and US were the direct factors predicting parents' CIU. PEU had a direct prediction to parents' CIU. This finding was the same as that of the study of Roca and Gagné (2008), in which PEU can predict continuance intention. SN had a direct prediction to CIU, which was the same as the findings of other studies (Lee, 2010; Mouakket, 2015; Liu et al., 2021). In these studies, satisfaction was the only factor predicting CIU. Other factors indirectly influenced CIU through satisfaction. Related studies also had a similar result, namely that satisfaction had the greatest prediction (Lee, 2010; Limayem \& Cheung, 2008; Shi et al., 2010; Kumar et al., 2018). However, according to Tam et al. (2018), satisfaction and performance expectancy were

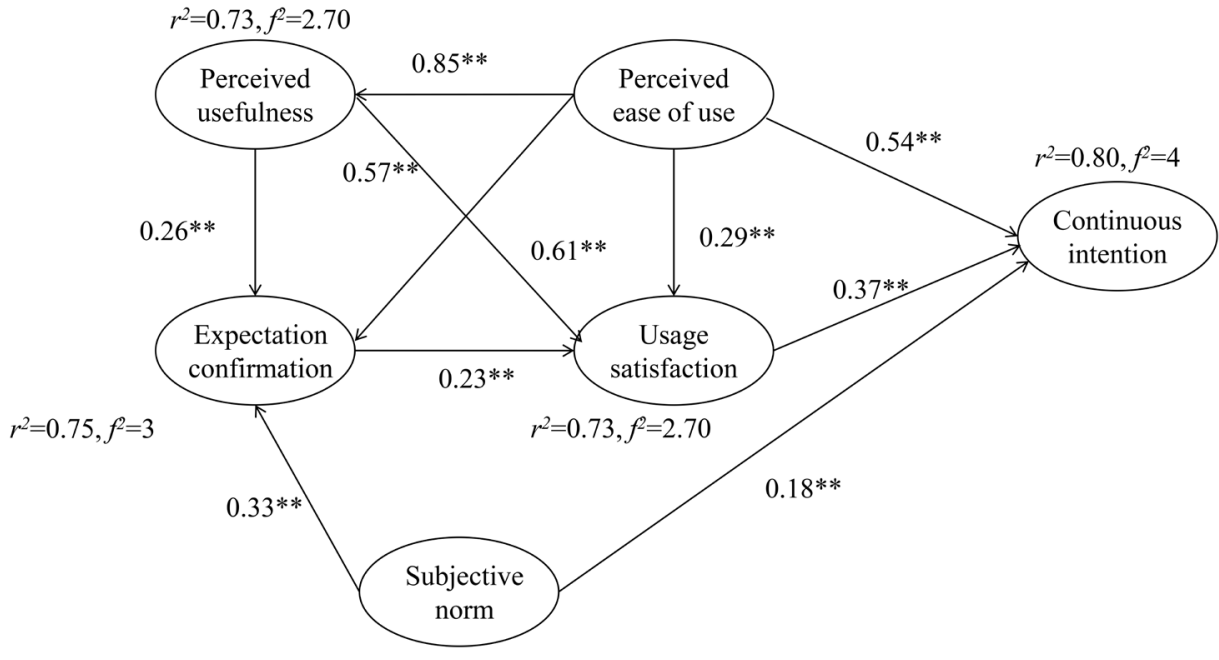

Note: ${ }^{* *} p<0.01,{ }^{* * *} p<0.001$.

Figure 4. Verified research model. 
the factors which can predict continuance intention to use mobile apps. Partially inconsistent with previous research, the results of this study showed that other people's decisions about using the SCS had direct prediction on the parents' $\mathrm{CIU}$, and the evaluation of the usage of the system could also directly predict their intention, which indicated that $\mathrm{H} 1, \mathrm{H} 9$ and $\mathrm{H} 10$ were positively supported.

The result of this study revealed that satisfaction was not the most important variable predicting the parents' CIU. The satisfaction variable was predicted by perceived usefulness and confirmation based on the post-Acceptance Model of IS continuance (Bhattacherjee, 2001). The study found that satisfaction was not only predicted by the two variables, but also perceived ease of use, which was consistent with the study of Gan and Balakrishnan (2018). This result of this study was also similar to the finding of the Post-Acceptance Model of IS continuance (Bhattacherjee, 2001). Parents had their own judgment and wisdom to evaluate and decide whether to use SCS after they used it, although other people's opinions and the first feelings about the system's usefulness about the educational value might influence them (Papadakis et al., 2019). To address this issue, the present study showed that $\mathrm{H} 2, \mathrm{H} 4, \mathrm{H} 5, \mathrm{H} 6, \mathrm{H} 7$, and $\mathrm{H} 8$ were all positively supported.

Hooi and Cho (2017) draw on self-awareness theory and ease of use to explain how user continuance intention may be predicted by digital devices. Supporting this, the ease of use related to the SCS device directly predicted parents' decisions in this study. The reason might be the friendly and simple operation of the system app. Wang et al. (2019) found that perceived ease of use did not have a significant impact on continuance intention to use a Cloud e-learning application, but Der Heijden (2004) proved that perceived ease of use has a positive impact on continuous use intention. However, perceived ease of use by parents could positively predict perceived usefulness and their CIU in this study, indicating that $\mathrm{H} 3$ and $\mathrm{H} 10$ were positively supported.

\section{Conclusion}

The sample parents applied the kindergarten SCS for two semesters. Their attitudes towards their kindergarten SCS CIU were valuable for the following development and implementation of the SCS. They could also address the gap in the literature on parents' views of CIU on the SCS. A number of implications are proposed based on the results of this study.

The results show that the different factors directly or indirectly predict the kindergarten parents' CIU. Thus, designers and researchers can determine appropriate strategies for constructing a kindergarten SCS. First, PEU, SN, and US are the direct factors predicting the application of a SCS. The parents' decision of continuance intention to use the SCS is a comprehensive factor which combines others; thus, it can be concluded that more attention should be paid to the improvement of the system to satisfy the parents' need to know about the daily life of their children from the SCS. 
Second, parents' expectation confirmation is related to PU, PEU and SN. The latter three variables can predict parents' pre-use expectation. Although the advertising of the system and others' using experience results did have some predictive power on parents' CIU, the individual usage experience played the greatest role in the expectation confirmation. However, the result of this study reveals that if the pre-use expectations are high, the final expectation of confirmation may be low. Thus, the designers of the system can add more friendly functions to the SCS system to enhance parents' perceived usefulness, for example, the function of a reminder service for parents to make sure that their child wears the wristband to school every day.

Third, from the survey, there were still $30.8 \%$ of parents who checked the app once every few days, which cannot get their children's information in time. Thus, how to promote parents' common and frequent usage of the system remains an issue. Thus, it is necessary to design an APP to introduce to parents how to get familiar with the system, for example, information about how to communicate with the teachers and others through the app.

Only 18 classes in three kindergartens applied the SCS, which may lead to the result of low mean value and high standard deviation value of PEU in this study. Future studies need to increase the sample size and include more kindergarten parents from different schools and different areas. Along with the development of the construction of the SCS, there may be new functions to serve kindergarten parents, and effects on the change of parents' needs and attitude. Following these changes, future studies may focus on the related factors of CIU with new versions of the SCS.

\section{Acknowledgements}

This research was supported by a grant from the Priority Academic Program Development of Jiangsu Higher Education Institutions in China.

\section{Author Contributions}

This work is the result of the collaboration of all authors. All authors have equally contributed, reviewed, and improved the manuscript. All authors have revised and approved the final manuscript.

\section{Conflicts of Interest}

The authors declare no conflicts of interest regarding the publication of this paper.

\section{References}

Abdrabbah, S. B., Ayachi, R., \& Amor, N. B. (2018). Social Activities Recommendation System for Students in Smart Campus. International Conference on Intelligent Interactive Multimedia Systems and Services, Vol. 76, 461-470.

https://doi.org/10.1007/978-3-319-59480-4 46 
Anderson, J. C., \& Gerbing, D. W. (1988). Structural Equation Modeling in Practice: A Review and Recommended Two-Step Approach. Psychological Bulletin, 103, 411-423. https://doi.org/10.1037/0033-2909.103.3.411

Bentler, P. M. (1990). Comparative Fit Indexes in Structural Models. Psychological Bulletin, 107, 238-246. https://doi.org/10.1037/0033-2909.107.2.238

Bentler, P. M., \& Bonnet, D. C. (1980). Significance Tests and Goodness of Fit in the Analysis of Covariance Structures. Psychological Bulletin, 88, 588-606. https://doi.org/10.1037/0033-2909.88.3.588

Bhattacherjee, A. (2001). Understanding Information Systems Continuance: An Expectation-Confirmation Model. Management Information Systems Quarterly, 25, 351-370. https://doi.org/10.2307/3250921

Bi, T. P., Yang, X. M., \& Ren, M. L. (2017). The Design and Implementation of Smart Campus System. Journal of Computers, 12, 527-533. https://doi.org/10.17706/jcp.12.6.527-533

Cadotte, E. R., Woodruff, R. B., \& Jenkins, R. L. (1987). Expectations and Norms in Models of Consumer Satisfaction, Journal of Marketing Research, 24, 305-314. https://doi.org/10.1177/002224378702400307

Chao, H. (2017). On Study of Building Smart Campus under Conditions of Cloud Computing and Internet of Things. IOP Conference Series: Earth and Environmental Science, 100, Article ID: 012118. https://doi.org/10.1088/1755-1315/100/1/012118

Cheng, M., \& Yuen, A. H. K. (2018). Student Continuance of Learning Management System Use: A Longitudinal Exploration. Computers \& Education, 120, 241-253. https://doi.org/10.1016/j.compedu.2018.02.004

Chou, H. K., Lin, I. C., Woung, L. C., \& Tsai, M. T. (2012). Engagement in E-Learning Opportunities: An Empirical Study on Patient Education Using Expectation Confirmation Theory. Journal of Medical Systems, 36, 1697-1706.

https://doi.org/10.1007/s10916-010-9630-9

Coccoli, M., Guercio, A., Maresca, P., \& Stanganelli, L. (2014). Smarter Universities: A Vision for the Fast Changing Digital Era. Journal of Visual Languages \& Computing, 25, 1003-1011. https://doi.org/10.1016/j.jvlc.2014.09.007

Davis, F. D. (1989). Perceived Usefulness, Perceived Ease of Use, and User Acceptance of Information Technology. Management Information Systems Quarterly, 3, 319-339. https://doi.org/10.2307/249008

Der Heijden, H. V. (2004). User Acceptance of Hedonic Information Systems. Management Information Systems Quarterly, 28, 695-704. https://doi.org/10.2307/25148660

Ebbeck, M., Yim, H. Y. B., Chan, Y., \& Goh, M. (2016). Singaporean Parents' Views of Their Young Children's Access and Use of Technological Devices. Early Childhood Education Journal, 44, 127-134. https://doi.org/10.1007/s10643-015-0695-4

Erdogan, N. I., Johnson, J. E., Dong, P. I., \& Qiu, Z. (2019). Do Parents Prefer Digital Play? Examination of Parental Preferences and Beliefs in Four Nations. Early Childhood Education Journal, 47, 131-142. https://doi.org/10.1007/s10643-018-0901-2

Fornell, C., \& Larcker, D. (1981). Evaluating Structural Equation Models with Unobservable Variables and Measurement Error. Journal of Marketing Research, 18, 39-50. https://doi.org/10.1177/002224378101800104

Foster, J. J., Barkus, E., \& Yavorsky, C. (2006). Understanding and Using Advanced Statistics: A Practical Guide for Students. SAGE. https://doi.org/10.4135/9780857020154

Fritz, C. O., Morris, P. E., \& Richler, J. J. (2012). Effect Size Estimates: Current Use, Calculations, and Interpretation. Journal of Experimental Psychology: General, 141, 2-18. 
https://doi.org/10.1037/a0024338

Gan, C. L., \& Balakrishnan, V. (2018). Mobile Technology in the Classroom: What Drives Student-Lecturer Interactions? International Journal of Human-Computer Interaction, 34, 666-679. https://doi.org/10.1080/10447318.2017.1380970

Gao, Q., Yan, Z., Wei, C., Liang, Y., \& Mo, L. (2017). Three Different Roles, Five Different Aspects: Differences and Similarities in Viewing School Mobile Phone Policies among Teachers, Parents, and Students. Computers \& Education, 106, 13-25. https://doi.org/10.1016/j.compedu.2016.11.007

Hair, J. F., Black, W. C., Babin, B. J., \& Anderson, R. E. (2014). Multivariate Data Analysis (7th ed.). Pearson Prentice Hall.

Hair, J. F., Black, W. C., Babin, B. J., Anderson, R. E., \& Tatham, R. L. (2010). Multivariate Data Analysis (7th ed.). Pearson Education Inc.

He, Y., Stojmenovic, I., Liu, Y., \& Gu, Y. (2014). Smart City. International Journal of Distributed Sensor Networks, 10, Article ID: 867593. https://doi.org/10.1155/2014/867593

Hooi, R., \& Cho, H. (2017). Virtual World Continuance Intention. Telematics and Informatics, 34, 1454-1464. https://doi.org/10.1016/j.tele.2017.06.009

Hsiao, C. H., Chang, J. J., \& Tang, K.Y. (2016). Exploring the Influential Factors in Continuance Usage of Mobile Social Apps: Satisfaction, Habit, and Customer Value Perspectives. Telematics and Informatics, 33, 342-355.

https://doi.org/10.1016/j.tele.2015.08.014

Joo, Y. J., So, H. J., \& Kim, N. H. (2018). Examination of Relationships among Students' Self-Determination, Technology Acceptance, Satisfaction, and Continuance Intention to Use K-MOOCs. Computers \& Education, 122, 260-272.

https://doi.org/10.1016/j.compedu.2018.01.003

Kline, R. B. (2005). Principles and Practice of Structural Equation Modeling (2nd ed.). The Guilford Press.

Kumar, R. R., Israel, D., \& Malik, G. (2018). Explaining Customer's Continuance Intention to Use Mobile Banking Apps with an Integrative Perspective of ECT and Self-Determination Theory. Pacific Asia Journal of the Association for Information Systems, 10, 79-112. https://doi.org/10.17705/1pais.10204

Kwok, L. F. (2015). A Vision for the Development of i-Campus. Smart Learning Environments, 2, 1-12. https://doi.org/10.1186/s40561-015-0009-8

Lau, E. Y. H., \& Ng, M. L. (2019). Are They Ready for Home-School Partnership? Perspectives of Kindergarten Principals, Teachers and Parents. Children and Youth Services Review, 99, 10-17. https://doi.org/10.1016/j.childyouth.2019.01.019

Lee, M. C. (2010). Explaining and Predicting Users' Continuance Intention toward e-Learning: An Extension of the Expectation-Confirmation Model. Computers and Education, 54, 506-516. https://doi.org/10.1016/j.compedu.2009.09.002

Lee, S. M., Seo, H. A., \& Han, H. J. (2014). Use of Smart Devices of Infants and Preschool-Children and Their Mothers' Perceptions. Korean Journal of Childcare and Education, 10, 111-131. https://doi.org/10.14698/jkcce.2014.10.2.111

Limayem, M., \& Cheung, C. M. K. (2008). Understanding Information Systems Continuance. The Case of Internet-Based Learning Technologies. Information and Management, 45, 227-232. https://doi.org/10.1016/j.im.2008.02.005

Liu, H. H., Shao, M. M., Liu, X. H., \& Zhao, L. (2021), Exploring the Influential Factors on Readers' Continuance Intentions of E-Book APPs: Personalization, Usefulness, Playfulness, and Satisfaction. Frontiers in Psychology, 12, 262-273.

https://doi.org/10.3389/fpsyg.2021.640110 
Liu, J., \& Liu, M. (2020). Application Design and Implementation for Smart Kindergarten. Journal of Physics Conference Series, 1584, Article ID: 012009. https://doi.org/10.1088/1742-6596/1584/1/012009

Luo, L. (2018). Data Acquisition and Analysis of Smart Campus Based on Wireless Sensor. Wireless Personal Communications, 102, 2897-2911. https://doi.org/10.1007/s11277-018-5314-4

Meyer, M., Adkins, V., Yuan, N., Weeks, H. M., Chang, Y. J., \& Radesky, J. (2019). Advertising in Young Children's Apps: A Content Analysis. Journal of Developmental and Behavioral Pediatrics, 40, 32-39. https://doi.org/10.1097/DBP.0000000000000622

Montessori, M. (1967). The Discovery of the Child(M. J. Costello, Trans.). Ballantine.

Montessori, M. (1989a). Creative Development in the Child I (R. Ramachandran, Trans.). Kalakshetra Press.

Montessori, M. (1989b). Creative Development in the Child II (R. R, Trans.). Kalakshetra Press.

Mouakket, S. (2015). Factors Influencing Continuance Intention to Use Social Network Sites: The Facebook Case. Computers in Human Behavior, 53, 102-110. https://doi.org/10.1016/j.chb.2015.06.045

Nunnally, J. C., \& Bernstein, I. H. (1994). Psychometric Theory(3rd ed.). McGraw-Hill.

Oliver, R. L. (1980). A Cognitive Model of the Antecedents and Consequences of Satisfaction Decisions. Journal of Marketing Research, 17, 460-469. https://doi.org/10.1177/002224378001700405

Pagliaro, F., Mattoni, B., Gugliermenti, F., Bisegna, F., Azzaro, B., Tomei, F., \& Catucci, S. (2016). A Roadmap toward the Development of Sapienza Smart Campus. 2016 IEEE 16th International Conference on Environment and Electrical Engineering, Florence, 7-10 June 2016, 1-6. https://doi.org/10.1109/EEEIC.2016.7555573

Papadakis, S., Zaranis, N., \& Kalogiannaki, M. (2019). Parental Involvement and Attitudes towards Young Greek Children's Mobile Usage. International Journal of Child-Computer Interaction, 22, Article ID: 100144. https://doi.org/10.1016/j.ijcci.2019.100144

Raes, A., Vanneste, P., Pieters, M., Windey, I., Van Den Noortgate, W., \& Depaepe, F. (2020). Learning and Instruction in the Hybrid Virtual Classroom: An Investigation of Students' Engagement and the Effect of Quizzes. Computers \& Education, 143, Article ID: 103682. https://doi.org/10.1016/j.compedu.2019.103682

Rahman, M. N. A., Syed-Zamri, S. N. A., \& Eu, L. K. (2017). A Meta-Analysis Study of Satisfaction and Continuance Intention to Use Educational Technology. International Journal of Academic Research in Business and Social Sciences, 7, 1059-1072. https://doi.org/10.6007/IJARBSS/v7-i4/2915

Roca, J. C., \& Gagné, M. (2008). Understanding e-Learning Continuance Intention in the Workplace: A Self-Determination Theory Perspective. Computers in Human Behavior, 24, 1585-1604. https://doi.org/10.1016/j.chb.2007.06.001

Sanchez, A., \& Golding, I. (2013). Genetic Determinants and Cellular Constraints in Noisy Gene Expression. Science, 342, 1188-1193.

https://doi.org/10.1126/science.1242975

Sari, S. W., Ciptadi, P. W., \& Hardyanto, R. H. (2017). Study of Smart Campus Development Using Internet of Things Technology. IAES International Conference on Electrical Engineering, Computer Science and Informatics, Semarang, 23-25 November 2016, Article ID: 012032. https://doi.org/10.11591/eecsi.v3i1.1126

Shi, N., Lee, M. K. O., Cheung, C., \& Chen, H. (2010). The Continuance of Online Social Networks: How to Keep People Using Facebook? Proceedings of the 43rd Hawaii In- 
ternational Conference on Systems Science, Honolulu, 5-8 January 2010, 1-10. https://doi.org/10.1109/HICSS.2010.369

Sin, S. J., \& Kim, K. (2013). International Students' Everyday Life Information Seeking: The Informational Value of Social Networking Sites. Library \& Information Science Research, 35, 107-116. https://doi.org/10.1016/j.lisr.2012.11.006

Singh, A., Payal, A., \& Bharti, S. (2019). The Emerging IoT Paradigm: Visualizing inside Functionalities, Key Features, and Open Issues. Journal of Network and Computer Applications, 143, 111-151. https://doi.org/10.1016/j.jnca.2019.06.013

Steiger, J. H. (1990). Structural Model Evaluation and Modification: An Interval Estimation Approach. Multivariate Behavioral Research, 25, 173-180. https://doi.org/10.1207/s15327906mbr2502 4

Tabachnick, B. G., \& Fidell, L. S. (2007). Using Multivariate Statistics (5th ed.). Allyn and Bacon.

Tam, C., Santos, D., \& Oliveira, T. (2018). Exploring the Influential Factors of Continuance Intention to Use Mobile Apps: Extending the Expectation Confirmation Model. Information Systems Frontiers, 22, 243-257. https://doi.org/10.1007/s10796-018-9864-5

Torres-Sospedra, J., Avariento, J., Rambla, D., Montoliu, R., Casteleyn, S., Benedito-Bordonau, M., Gould, M., \& Huerta, J. (2015). Enhancing Integrated Indoor/Outdoor Mobility in a Smart Campus. International Journal of Geographical Information Science, 29, 1955-1968. https://doi.org/10.1080/13658816.2015.1049541

Van Merode, D., Tabunshchyk, G., Patrakhalko, K., \& Yuriy, G. (2016). Flexible Technologies for Smart Campus. International Conference on Remote Engineering and Virtual Instrumentation, Madrid, 24-26 February 2016, 64-68.

https://doi.org/10.1109/REV.2016.7444441

Venkatesh, V., Morris, M. G., Davis, G. B., \& Davis, F. D. (2003). User Acceptance of Information Technology: Toward a Unified View. Management Information Systems Quarterly, 27, 425-478. https://doi.org/10.2307/30036540

Wang, L.Y. K., Lew, S. L., Lau, S. H., \& Leow, M. C. (2019). Usability Factors Predicting Continuance of Intention to Use Cloud e-Learning Application. Heliyon, 5, e01788. https://doi.org/10.1016/j.heliyon.2019.e01788

Wang, Y., \& Yan, X. (2018). Research and Implementation of Wisdom Campus System Based on Android Platform. International Conference on Education \& Management, Vol. 53, 151-154. https://doi.org/10.2991/icem-17.2018.33

Xu, X., Wang, Y., \& Yu, S. (2018). Teaching Performance Evaluation in Smart Campus. IEEE Access, 6, 77754-77766. https://doi.org/10.1109/ACCESS.2018.2884022

Yang, A. M., Li, S. S., Ren, C. H., Liu, H. X., Han, Y., \& Liu, L. (2018). Situational Awareness System in the Smart Campus. IEEE Access, 6, 63976-63986. https://doi.org/10.1109/ACCESS.2018.2877428

Zaballos, A., Briones, A., Massa, A., Centelles, P., \& Caballero C. V. (2020). A Smart Campus' Digital Twin for Sustainable Comfort Monitoring. Sustainability, 12, 9196. https://doi.org/10.3390/su12219196

Zhao, J., Li, J., \& Jia, J. (2021a). A Study on Posture-Based Teacher-Student Behavioral Engagement Pattern. Sustainable Cities and Society, 67, Article ID: 102749. https://doi.org/10.1016/j.scs.2021.102749

Zhao, L., He, W., \& Su, Y. S. (2021b). Innovative Pedagogy and Design-Based Research on Flipped Learning in Higher Education. Frontiers in Psychology, 12, 230. https://doi.org/10.3389/fpsyg.2021.577002 